\title{
Synergistic antitumor activity of low-dose c-Met tyrosine kinase inhibitor and sorafenib on human non-small cell lung cancer cells
}

\author{
LING FU ${ }^{1}$, LIANG GUO ${ }^{2}$, YI ZHENG ${ }^{1}$, ZHENYU ZHU $^{3}$, MINGYUE ZHANG $^{4}$, \\ XIAOHUA ZHAO ${ }^{4}$ and HONGXUE CUI ${ }^{4}$
}

\author{
${ }^{1}$ Department of Oncology, Affiliated Hospital of Weifang Medical University, Weifang, Shandong 261031; \\ ${ }^{2}$ Department of Cardio-Thoracic Surgery, Xinhua Hospital, Shanghai Jiao Tong University School of Medicine, \\ Shanghai 200092; ${ }^{3}$ Surgical Ward 4, Shandong Tumor Hospital, Jinan, Shandong 250117; ${ }^{4}$ Department of Thoracic Surgery, \\ Affiliated Hospital of Weifang Medical University, Weifang, Shandong 261031, P.R. China
}

Received April 12,2017; Accepted December 8, 2017

DOI: $10.3892 / \mathrm{ol} .2018 .7933$

\begin{abstract}
Sorafenib is a multikinase inhibitor that is frequently used to treat various types of malignant tumors. However, it has been demonstrated that Sorafenib only has a moderate antitumor efficacy and is associated with numerous side effects in non-small cell lung cancer (NSCLC), which greatly limits its clinical application. The present study aimed to examine the effects of a combination of Sorafenib and low-dose PF-2341066, a selective c-Met tyrosine kinase inhibitor, on the proliferation, apoptosis and migration of the NSCLC cell line NCI-H1993. The data indicated that treatment with a combination of Sorafenib and low-dose PF-2341066 was able to significantly inhibit the proliferation and migration as well as promote the apoptosis, of NCI-H1993 cells, compared with treatment with Sorafenib or low-dose PF-2341066 alone. Further experiments indicated that the levels of phosphorylated epidermal growth factor receptor and c-Met were significantly decreased following the combined treatment of Sorafenib and PF-2341066, compared with the treatment with Sorafenib or PF-2341066 alone. The findings of the present study indicated that using a low-dose c-Met inhibitor enhances the antitumor activity of Sorafenib in NSCLC and may provide a novel strategy for the treatment of NSCLC.
\end{abstract}

\section{Introduction}

In 2012, lung cancer was the leading cause of cancer-associated mortality in males according to global cancer statistics (1). The 5-year survival rate for patients with non-small cell lung cancer (NSCLC), which accounts for $85-90 \%$ of all the lung cancer diagnoses, was $<20 \%(2,3)$. The first-line standard

Correspondence to: Dr Hongxue Cui, Department of Thoracic Surgery, Affiliated Hospital of Weifang Medical University, 2428 Yu He Road, Weifang, Shandong 261031, P.R. China

E-mail: cuihongxue@163.com

Key words: sorafenib, c-Met, non-small cell lung cancer, proliferation, apoptosis, migration treatment for NSCLC, including surgery, chemotherapy and radiotherapy, is selected depending on the disease and patient characteristics (4). Currently, platinum-based regimens are first-line chemotherapies; single-agent docetaxel, pemetrexed or erlotinib are prominent second-line therapies (5). However, no response or resistance to conventional chemotherapies is a problem when studying the pathological processes and new therapeutic strategies for lung tumors (6). Therefore, current therapies have been demonstrated to be inadequate, and novel strategies are required (7).

Sorafenib is a multi-tyrosine kinase inhibitor that blocks Raf kinases, platelet-derived growth factor receptors and vascular endothelial growth factor receptors (VEGFR) (8). Sorafenib is frequently used in the clinical treatment of unresectable hepatocellular carcinoma and advanced renal cell carcinoma $(9,10)$. Ongoing clinical trials are studying its activity in other types of malignancy, including NSCLC $(11,12)$. The effects of Sorafenib have been confirmed effect in preclinical models of NSCLC $(13,14)$. However, Sorafenib does not improve the overall survival time of patients with advanced NSCLC (15). Furthermore, Sorafenib has a number of side effects, including hand-foot syndrome, rash, diarrhea, hypertension and fatigue, which limit its application in the treatment of NSCLC. Generally, the majority of these aforementioned side effects are dose-dependent (16). Therefore, increasing the sensitivity of tumor tissues to Sorafenib and thus reducing the required dose, warrants further investigation.

c-Met is another important member of the receptor tyrosine kinase superfamily (17). It has been demonstrated that c-Met is upregulated or partially activated by mutation in NSCLC (18). Phosphatidylinositol-3-kinase (PI3K)-AKT and mitogen-activated protein kinase (MAPK) are common downstream pathways of the hepatocyte growth factor (HGF)/c-Met and VEGF signaling pathways (19). The c-Met/HGF pathway serves an important role in proliferation, apoptosis, invasion, metastasis of tumor cells and angiogenesis (20). Furthermore, treatments targeting the HGF/c-Met signaling pathway have been proposed for multiple types of cancer (21). Specific c-Met small molecule inhibitors, including SU-11274 and PHA-665752, have emerged as treatments for malignant tumors (22). PF-2341066 is an effective and orally available 
ATP-competitive small molecule compound that targets c-Met, blocking its phosphorylation (23).

Previous studies have demonstrated that selective c-Met inhibitors can attenuate or promote the antitumor activities of different molecularly-targeted therapies, including the VEGFR-inhibitor, pazopanib, and the epidermal growth factor receptor (EGFR)-inhibitor erlotinib (24,25). Furthermore, c-Met amplification is one of the most important mechanisms that facilitate resistance to gefitinib by re-activating the AKT and extracellular signal-regulated kinase (ERK) pathways in NSCLC (26); however, whether PF-2341066 can affect the antitumor activities of Sorafenib remains unknown. In the present study, whether or not PF-2341066 can effectively inhibit the phosphorylation of c-Met in NSCLC cells was investigated. Following this, the antitumor potential of the combined PF-2341066 and Sorafenib treatment in human NSCLC cells was studied as a potential comprehensive treatment for this disease.

\section{Materials and methods}

Materials. Sorafenib, (4-[4-[[4-chloro-3-(trifluoromethyl) phenyl]carbamoylamino]phenoxy]-N-methylpyridine-2-carboxamide) was purchased from Bayer AG (Leverkusen, Germany); PF-2341066 was obtained from Pfizer, Inc. (New York, NY USA). Dimethyl sulfoxide (DMSO) was purchased from Sigma-Aldrich (Merck KGaA, Darmstadt, Germany).

Cell culture. The human NSCLC cell line NCI-H1993 was provided by the Cell Resource Center of the Shanghai Institutes for Biological Sciences of the Chinese Academy of Sciences (Shanghai, China). NCI-H1993 cells were maintained in RPMI 1640 medium (Invitrogen; Thermo Fisher Scientific, Inc., Waltham, MA, USA) supplemented with 10\% HyClone fetal bovine serum (FBS; GE Healthcare Life Sciences, Logan, UT, USA), penicillin (100 U/ml; Sigma-Aldrich; Merck KGaA) and streptomycin (100 mg/ml; Sigma-Aldrich; Merck $\mathrm{KGaA})$. The cells were cultured in a humidified incubator at $37^{\circ} \mathrm{C}$ with $5 \% \mathrm{CO}_{2}$.

Cell proliferation and colony formation assays. NCI-H1993 cells $\left(8 \times 10^{3} /\right.$ well) were seeded into 96 -well plates and cultured in RPMI-1640 medium with the designated concentrations of Sorafenib and/or PF-2341066 dissolved in DMSO for 24, 48, 72 and $96 \mathrm{~h}$ at $37^{\circ} \mathrm{C}$ and $5 \% \mathrm{CO}_{2}$. Cell proliferation assays were performed using a Cell Counting Kit-8 assay kit (Beyotime Institute of Biotechnology, Haimen, China), according to the manufacturer's instructions. The absorbance value in each well was measured at a wavelength of $490 \mathrm{~nm}$. DMSO was used as negative control. The experiments were repeated three times.

For the soft agar assay, each well of a 6 -well plate was setup containing a bottom layer of $1.2 \%$ agarose, a middle layer of $0.7 \%$ agarose with 2,000 cells and a top layer of RPMI-1640 medium with designated concentrations of Sorafenib and/or PF-2341066 dissolved in DMSO $(0.5 \mu \mathrm{M}$ PF, $2.5 \mu \mathrm{M}$ Sora, $0.5 \mu \mathrm{M} \mathrm{PF}+2.5 \mu \mathrm{M}$ Sora). The medium in the top layer was changed every 6 days. After 28 days, the colonies were counted.

Apoptosis assay. Apoptosis was assessed with an Annexin VFITC/PI Apoptosis Detection kit (Nanjing Keygen Biotech.
Co., Ltd., Nanjing, China), according to the manufacturer's protocol. Briefly, $1 \times 10^{5}$ cells were seeded into 6-well plates and incubated with designated concentrations of Sorafenib and/or PF-2341066 dissolved in DMSO $(0.5 \mu \mathrm{M}$ PF, $2.5 \mu \mathrm{M}$ Sora, $0.5 \mu \mathrm{M} \mathrm{PF}+2.5 \mu \mathrm{M}$ Sora) for $24 \mathrm{~h}$ at $37^{\circ} \mathrm{C}$ and $5 \% \mathrm{CO}_{2}$. Then, the cells were harvested. The cells were re-suspended in $100 \mu \mathrm{l} 1 \mathrm{X}$ binding buffer from the Apoptosis Detection kit and incubated for $15 \mathrm{~min}$ at room temperature. A total of $4 \mu \mathrm{l}$ Annexin V-fluorescein isothiocyanate (FITC) and $1 \mu \mathrm{l}$ propidium iodide were added and cultured for $10 \mathrm{~min}$ at room temperature. Finally, $400 \mu 1 \mathrm{X}$ binding buffer was added to each sample. A CytoFLEX flow cytometer (Beckman Coulter, Inc., Brea, CA, USA) was used to analyze Annexin V-FITC-positive cells and FlowJo (v 9.3.2; Tree Star, Inc., Ashland, OR, USA) was used for the data analysis. DMSO was used as negative control. The experiments were repeated three times.

Migration assay. Migration assays were performed using polycarbonate membrane chambers (pore size, $8.0 \mu \mathrm{m}$; EMD Millipore, Billerica, MA, USA) as previously demonstrated (27). Briefly, NCI-H1993 cells $\left(1 \times 10^{5}\right)$ were suspended in $100 \mu \mathrm{l}$ RPMI-1640 medium containing $1.5 \%$ FBS were added to the upper chambers. The lower compartments of the chamber were filled with RPMI-1640 medium containing 15\% FBS and the designated concentrations of Sorafenib and/or PF-2341066 dissolved in DMSO (0.5 $\mu \mathrm{M}$ PF, $2.5 \mu \mathrm{M}$ Sora, $0.5 \mu \mathrm{M} \mathrm{PF}+2.5 \mu \mathrm{M}$ Sora). Following incubation for $24 \mathrm{~h}$ at $37^{\circ} \mathrm{C}$ and $5 \% \mathrm{CO}_{2}$, the cells that had migrated through the filters were fixed using $4 \%$ paraformaldehyde and stained with $0.05 \%$ crystal violet $5 \mathrm{~min}$ at room temperature. The migrated cells were counted under a light microscope at magnification, $\mathrm{x} 200$. A total of 6 fields of cells were counted using ImageJ Software (National institutes of Health, Bethesda, MD, USA).

Western blotting. Cells were lysed in Triton lysing buffer (Sigma-Aldrich; Merck KGaA) and centrifuged at 12,000 x g at $4^{\circ} \mathrm{C}$ for $15 \mathrm{~min}$. Protein concentrations were measured using a BCA kit. Total protein lysates $(10 \mu \mathrm{g})$ were separated by $10 \%$ SDS-PAGE and transferred onto Immobilon-P polyvinylidene difluoride membranes (EMD Millipore), subsequently blocked with $5 \%$ bovine serum albumin (Sigma-Aldrich; Merck $\mathrm{KGaA}$ ) at $37^{\circ} \mathrm{C}$ for $1 \mathrm{~h}$. The blots were probed with anti-c-Met (cat. no. 3127; dilution, 1:1,000; Cell Signaling Technology, Inc., Danvers, MA, USA), anti-phospho (p)-Met (Tyr1234/1235, Tyr1349; cat. no. 3077; dilution, 1:1,000; Cell Signaling Technology, Inc.), anti-p-AKT (473; cat. no. 4060; dilution, 1:1,000; Cell Signaling Technology, Inc.), anti-AKT (cat. no. 4691; dilution, 1:1,000; Cell Signaling Technology, Inc.), anti-p-ERK (Thr202/Tyr204) (cat. no. 4370; dilution, 1:1,000; Cell Signaling Technology, Inc.), anti-ERK (cat. no. 4695; dilution, 1:1,000; Cell Signaling Technology, Inc.), anti-p-c-Jun N-terminal kinase (JNK; Thr183/Tyr185) (cat. no. 9255; dilution, 1:1,000; Cell Signaling Technology, Inc.), anti-JNK (cat. no. 9252; dilution, 1:1,000; Cell Signaling Technology, Inc.), anti-p-p38 (cat. no. 4511; Thr180/Tyr182; dilution, 1:1,000; Cell Signaling Technology, Inc.), anti-p38 (cat. no. 8690; dilution, 1:1,000; Cell Signaling Technology, Inc.) and anti-poly-ADP-ribose polymerase (cat. no. 9532; PARP 1;1000; Cell Signaling Technology, Inc., Danvers, MA, USA) incubating overnight at $4^{\circ} \mathrm{C}$ followed by either 
anti-rabbit or anti-mouse horseradish peroxidase-conjugated IgG secondary antibodies (cat. no. 4410; dilution, 1:2,000; Cell Signaling Technology, Inc.) incubating for $1 \mathrm{~h}$ at room temperature. Immunoreactive bands were detected using an ECL system (Pierce; Thermo Fisher Scientific, Inc.). $\beta$-actin (cat. no. SAB3500350; dilution, 1:5,000; Sigma-Aldrich; Merck KGaA) was used as an internal control.

Statistical analysis. Data are expressed as the mean \pm standard error and were analyzed using the GraphPad Prism software (version 5.0; GraphPad Software, Inc., La Jolla, CA, USA). The datasets were compared using the two-tailed unpaired Student's t-test. Multiple comparisons were tested with two-way analysis of variance, followed by Bonferroni's post hoc test. A value of $\mathrm{P}<0.05$ was considered to indicate statistically significance.

\section{Results}

PF-2341066 inhibits the phosphorylation of $c$-Met in NCI-H1993 cells. A previous study demonstrated that c-Met and its receptor are overexpressed by $\sim 70$ and $40 \%$ of human lung cancer tissues, respectively (28). However, $c$-Met gene amplification and activation was exhibited in NCI-H1993 cells but not NCI-H1975 or A549 cells $(29,30)$. In the present study, the expression levels of c-Met in NCI-H1993 cells were examined by western blot analysis (Fig. 1). The specific c-Met inhibitors, PF-2341066 and SU-11274, were able to inhibit the phosphorylation of c-Met in NCI-H1993 cells (Fig. 1).

c-Met inhibitors increase the effects of Sorafenib on proliferation of NSCLC cells. To determine whether increased c-Met phosphorylation following treatment with Sorafenib mediates the growth of NSCLC cells, the effects of Sorafenib and/or PF-2341066 treatment on the proliferation of NCI-H1993 cells were analyzed. As presented in Fig. 2A, blocking c-Met activation with a low-dose of PF-2341066 did not significantly increase the Sorafenib-induced inhibition of proliferation of NCI-H1993 cells compared with the vehicle-treated cells. However, the colony formation ability of NCI-H1993 cells was notably blocked following the combined treatment of Sorafenib and a low-dose of PF-2341066 compared with the vehicle-treated cells (Fig. 2B). This indicated that treatment with a combination of Sorafenib and a low-dose of PF-2341066 was able to inhibit the growth of NSCLC cells.

A low-dose of c-Met inhibitor facilitates Sorafenib-induced apoptosis of NSCLC cells. Next, the efficiency of a combination of PF-2341066 and Sorafenib in inducing the apoptosis of NCI-H1993 cells was examined. The percentage of apoptotic cells was higher in the cells that were treated with a combination of Sorafenib and a low-dose of PF-2341066 compared with cells treated with Sorafenib alone or a low-dose of PF-2341066 alone (Fig. 3A and B). In addition, the cell extracts were analyzed for the expression of PARP (an endogenous substrate of caspase-3 and -7) and of cleaved caspase-3, which is associated with programmed cell death. Notably, the addition of the c-Met inhibitor markedly increased the level of cleaved PARP in NCI-H1993 cells that were treated with Sorafenib (Fig. 3C and D). The data indicated that PF2341066 and Sorafenib act synergistically, at least in part through inducing cell apoptosis.

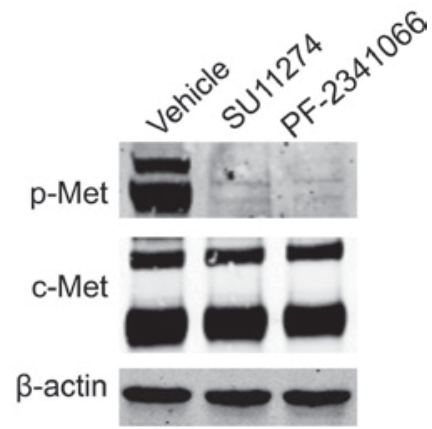

Figure 1. PF-2341066 inhibits c-Met phosphorylation in NCI-H1993 cells. (A) The levels of c-Met and p-Met proteins were evaluated using western blot analysis. NCI-H1993 cells were treated with $0.5 \mu \mathrm{M}$ SU11274 and $0.5 \mu \mathrm{M}$ PF-2341066, which was dissolved in dimethyl sulfoxide for $12 \mathrm{~h}$. $\beta$-actin was used as an internal control. p-Met and c-Met were represented by double bands. p, phosphorylated.
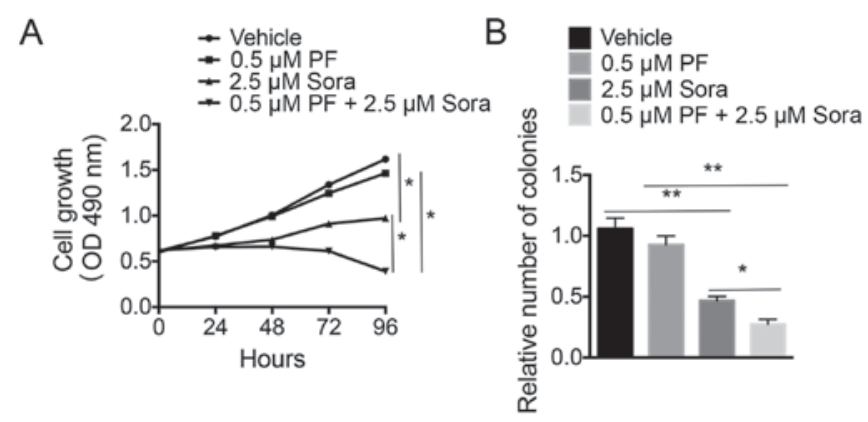

Figure 2. A low-dose of c-Met inhibitor increases the inhibitory effect of Sorafenib on the proliferation of non-small cell lung cancer cells. (A) Cell Counting Kit-8 cell proliferation assays were performed to detect the effect of Sorafenib and/or PF-2341066 on the proliferation of NCI-H1993 cells. NCI-H1993 cells were treated with various concentrations of Sorafenib and/or PF-2341066 dissolved in DMSO for 24, 48, 72 and 96 h, respectively. ${ }^{*} \mathrm{P}<0.05 ; \mathrm{n}=3$. (B) Colony formation assays were performed to detect the effect of Sorafenib and/or PF-2341066 on the proliferation of NCI-H1993 cells. NCI-H1993 cells were treated with the various concentrations of Sorafenib and/or PF-2341066 that was dissolved in DMSO. Graph shows the quantitation of colony formation assay. ${ }^{*} \mathrm{P}<0.05 ;{ }^{* *} \mathrm{P}<0.01 ; \mathrm{n}=4$. DMSO, dimethyl sulfoxide; OD, optical density; PF, PF-2341066; Sora, Sorafenib.

Blocking -Met signaling enhances the inhibitory effects of Sorafenib on the migration of NSCLC cells. The combined effect of low-dose PF-2341066 and Sorafenib on the migration of NSCLC cells was further investigated. The treatment of cells with a low-dose of PF-2341066 and Sorafenib significantly inhibited the migration of NCI-H1993 cells, compared with the groups treated with a low-dose of PF-2341066 or Sorafenib alone (Fig. 4A and B). Therefore, blocking c-Met signaling increased the sensitivity of NSCLC cells to Sorafenib by decreasing cell migration.

c-Met mediates Sorafenib sensitivity through the PI3K and MAPK signaling pathways in NSCLC. PI3K-AKT and MAPK are key downstream targets of the VEGFR and c-Met signaling pathways, both of which regulate the proliferation, apoptosis and migration of tumor cells (31). To investigate whether intracellular AKT, JNK, p38 MAPK or ERK signaling were involved in the antitumor ability of Sorafenib following the addition of low-dose PF-2341066, the expression levels of these proteins were analyzed (Fig. 5A). Notably, when compared 

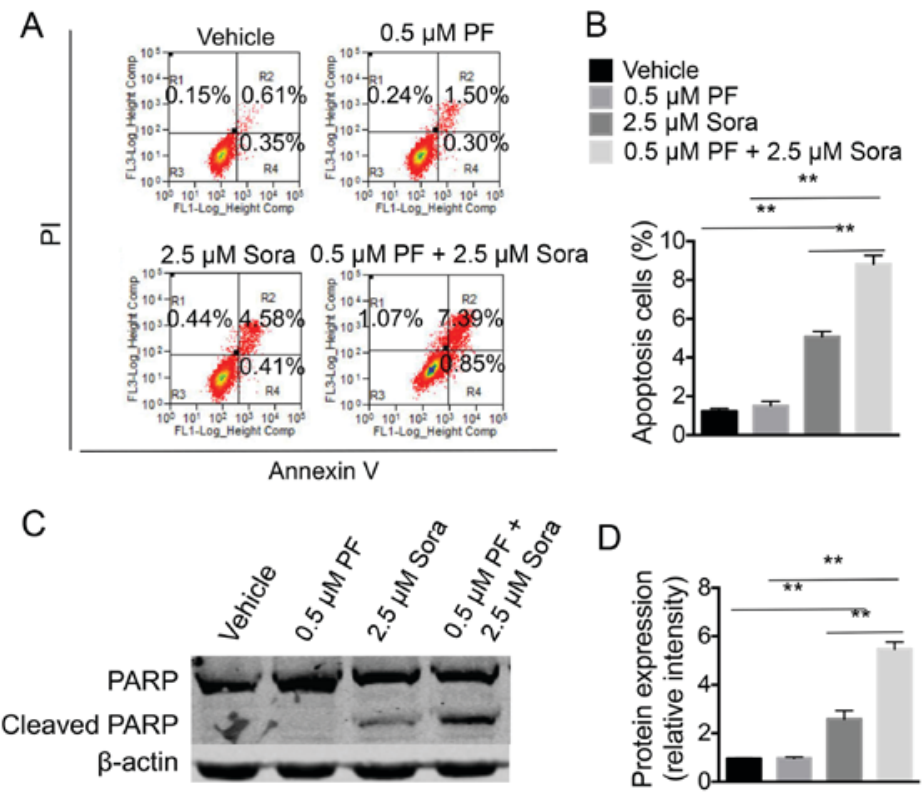

Figure 3. A low dose of c-Met inhibitor increases Sorafenib-induced apoptosis of non-small cell lung cancer cells. (A) Annexin V-FITC/PI staining for apoptosis in NCI-H1993 cells that were treated with various concentrations of Sorafenib and/or PF-2341066 dissolved in DMSO for $36 \mathrm{~h}$ was assessed using flow cytometry. (B) Quantitation of apoptotic cells; "P<0.05 as indicated; n=4. (C) Western blot analysis of the expression of cleaved PARP and total PARP. NCI-H1993 cells were treated with various concentrations of Sora and/or PF-2341066, which was dissolved in DMSO for $36 \mathrm{~h}$. $\beta$-actin was used as an internal control. (D) Densitometric quantification of western blot data. ${ }^{* *} \mathrm{P}<0.01$; $\mathrm{n}=3$. PARP, poly-ADP-ribose polymerase; PI, propidium iodide. PF, PF-2341066; Sora, Sorafenib

A

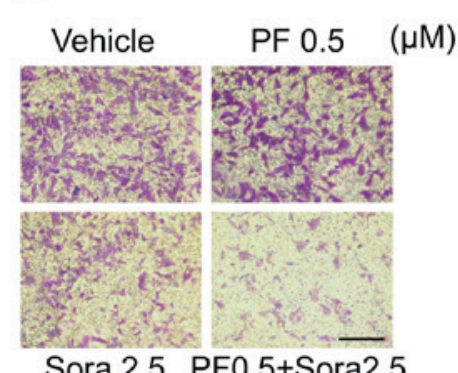

Sora 2.5 PF0.5+Sora2.5
B

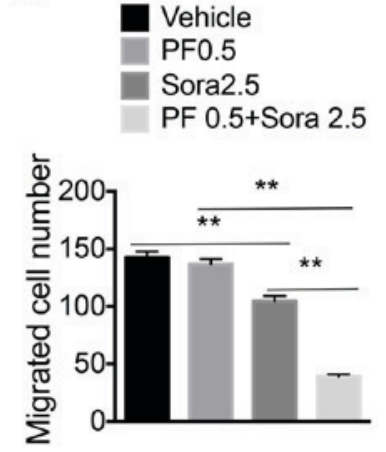

Figure 4. A low dose of c-Met inhibitor increases the effects of Sorafenib on the migration of non-small cell lung cancer cells. (A) The number of NCI-H1993 cells migrated that were treated with various concentrations of Sorafenib and/or PF-2341066 dissolved in DMSO for $24 \mathrm{~h}$ as indicated by Transwell assays. Scale bar, $100 \mu \mathrm{m}$. (B) Quantitation of the number of cells that migrated. ${ }^{* *} \mathrm{P}<0.01 ; \mathrm{n}=4$.

with single Sorafenib treatment, the phosphorylation of AKT, JNK and p38 MAPK was markedly inhibited following the addition of low-dose PF-2341066.; However, ERK phosphorylation was not significantly blocked by the combined treatment (Fig. 5B). These findings indicated that the PI3K-AKT and MAPK signaling pathways are required for c-Met-mediated Sorafenib sensitivity in NSCLC.

\section{Discussion}

NSCLC is one of the prevalent causes of cancer-associated mortality globally. Additionally, drug resistance in NSCLC further reduces the survival rate of patients $(28,32)$. Sorafenib has been demonstrated to have great effects on advanced
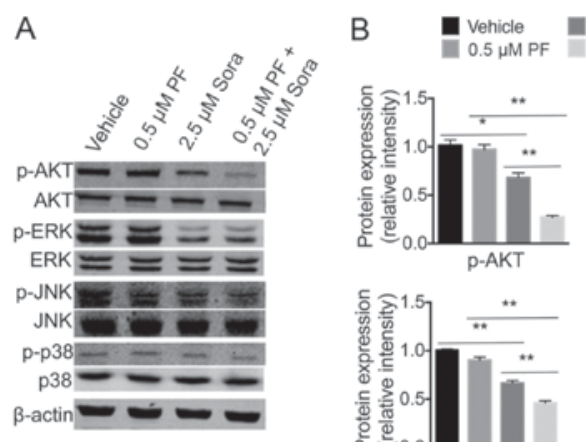

$2.5 \mu \mathrm{M}$ Sora $0.5 \mu \mathrm{M} \mathrm{PF}+2.5 \mu \mathrm{M}$ Sora
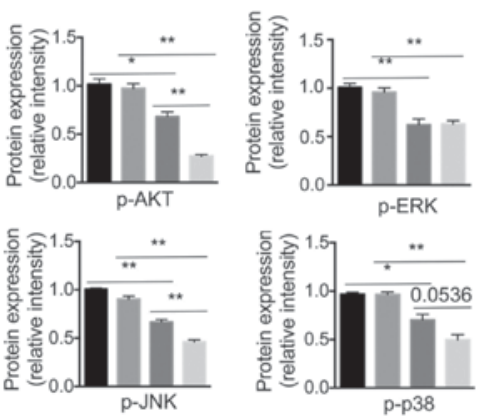

Figure 5. c-Met mediates sensitivity to Sorafenib via the phosphatidylinositol-3-kinase-AKT and mitogen-activated protein kinase signaling pathways in non-small cell lung cancer. (A) Expression levels of p-AKT (Ser473), AKT, p-ERK, ERK (Thr202/Tyr204), p-JNK (Thr183/Tyr185), JNK, p-p38 (Thr180/Tyr182) and p38 were evaluated using western blot analysis NCI-H1993 cells were treated with various concentrations of Sorafenib and/or PF-2341066 that was dissolved in DMSO for $2 \mathrm{~h}$. $\beta$-actin was used as an internal control. (B) Densitometric analysis of western blotting data; ${ }^{*} \mathrm{P}<0.05 ;{ }^{* *} \mathrm{P}<0.01 ; \mathrm{n}=3$. ERK, extracellular-signal-regulated kinase; JNK, c-Jun N-terminal kinase; p-, phosphorylated.

stages of liver and renal cancer (33). However, the efficacy of Sorafenib in NSCLC is frequently limited by its unfavorable pharmacokinetics, low tumor accumulation and other adverse effects (34).

In the present study, it was demonstrated that Sorafenib in combination with a low-dose of PF-2341066 was able to significantly inhibit the proliferation and migration, and promote the apoptosis, of NCI-H1993 cells, compared with treatment with Sorafenib or a low dose of PF-2341066 alone, indicating that a low dose of c-Met inhibitor is able to effectively increase the sensitivity of NSCLC cells to Sorafenib and subsequently decrease the dose requirement. Further experiments indicated 
that the PI3K-AKT and MAPK signaling pathways are biologically important for c-Met-mediated sensitivity to Sorafenib. Therefore, data demonstrated the success of combination therapy with a c-Met inhibitor and Sorafenib in the treatment of NSCLC in an initial in vitro study.

Raf is an important mediator of the small G-protein signaling step within the MAPK signaling pathway that is frequently activated in malignant tumors (35). Raf amplification or mutation leads to activation of the ERK signaling pathway, and therefore affects multiple tumor characteristics, including uncontrolled proliferation, evasion from apoptosis, invasion, distant metastasis, angiogenesis and immune evasion $(36,37)$. Sorafenib is able to effectively block the Ras/Raf/mitogen-activated protein kinase kinase (MEK)/ERK signaling pathway. Furthermore, Sorafenib inhibits the VEGF signaling pathway, as it is a multikinase inhibitor (38). It has been confirmed that molecular-targeting drugs act in a dose-dependent manner in NSCLC. This is because development of drug resistance patients with NSCLC is easy as a result of activation of alternative pathways (39-41). Previous studies have demonstrated that combined EGFR and a low-dose of c-Met inhibitors may be an effective treatment for NSCLC (42-44). The data from the present study are consistent with these previous reports, and further validate this conclusion at the cellular and molecular levels. Therefore, treatment with a low dose of c-Met inhibitor may increase the sensitivity to Sorafenib in the patients with NSCLC.

In the present study, the selective c-Met inhibitor PF-2341066 was used at a low concentration $(0.5 \mu \mathrm{M})$ in combination with Sorafenib $(2.5 \mu \mathrm{M})$, compared with as a single agent. This may markedly reduce side effects of Sorafenib in patients. Although a high dose $(>10 \mu \mathrm{M})$ of Sorafenib may achieve the same results as combined a low dose of Sorafenib and PF-2341066, this may result in more side effects for the patients. A combination of Sorafenib and a low-dose of PF-2341066 was able to significantly reduce the phosphorylation of AKT, JNK and p38 MAPK. However, the phosphorylation of ERK was not significantly blocked by the combined treatment, compared with treatment with a low dose of Sorafenib. Sorafenib may exerts its effects on ERK via the Ras/Raf/MEK/ERK signaling pathway (45), which may account for the similar levels of phosphorylated ERK observed between the groups treated with Sorafenib.

There were a number of limitations to the present study. Firstly, the study was conducted using only one cell line, and animal models were not used. Furthermore, a more detailed mechanism must be investigated in order to explain the effects of the combination of Sorafenib and low-dose c-Met inhibitor. It has also been demonstrated that tumor stem cells serve important roles in drug resistance in NSCLC (46). Future studies will be required to focus on the effect of this combined treatment on tumor stem cells.

In conclusion, the present study demonstrated that treatment with a combination of Sorafenib and a low dose of c-Met inhibitor was able to significantly inhibit the proliferation and migration as well as promote the apoptosis of NCI-H1993 cells, compared with treatment with Sorafenib alone. Furthermore, the present study indicated there are more therapeutic choices for patients with NSCLC who exhibit high c-Met and Raf/VEGFR expression levels, indicating the importance of individualized therapy for NSCLC.

\section{Acknowledgements}

The authors would like to thank Dr Yin Chen and Dr Fei Chen at Shanghai Xinhua Hospital for assistance with experiments. The authors also thank Dr James P. Mahaffey for editing the English text of a draft of this manuscript.

\section{References}

1. Torre LA, Bray F, Siegel RL, Ferlay J, Lortet-Tieulent J and Jemal A: Global cancer statistics, 2012. CA Cancer J Clin 65: 87-108, 2015.

2. Ott DE and Marcu KB: Molecular requirements for immunoglobulin heavy chain constant region gene switch-recombination revealed with switch-substrate retroviruses. Int Immunol 1: 582-591, 1989.

3. Jemal A, Siegel R, Xu J and Ward E: Cancer statistics, 2010. CA Cancer J Clin 60: 277-300, 2010.

4. Ettinger DS, Wood DE, Akerley W, Bazhenova LA, Borghaei H, Camidge DR, Cheney RT, Chirieac LR, D'Amico TA, Demmy TL, et al: Non-small cell lung cancer, version 1.2015. J Natl Compr Canc Netw 12: 1738-1761, 2014.

5. Liu CY, Wang CL, Li SH, Hsu PC, Chen CH, Lin TY, Kuo CH, Fang YF, Ko HW, Yu CT, et al: The efficacy of $40 \mathrm{mg}$ versus dose de-escalation to less than $40 \mathrm{mg}$ of afatinib (Giotrif) as the first-line therapy for patients with primary lung adenocarcinoma harboring favorable epidermal growth factor mutations. Oncotarget 8: 97602-97612, 2017.

6. Lategahn J, Keul M and Rauh D: Lessons to be learned: The molecular basis of kinase-targeted therapies and drug resistance in non-small cell lung cancer. Angew Chem Int Ed Engl: Nov 27, 2017 (Epub ahead of print).

7. Thabitha A, Dravid AA, Tripathi R and Lulu SS: Database of transcription factors in lung cancer (DBTFLC): A novel resource for exploring transcription factors associated with lung cancer. J Cell Biochem: Dec 13, 2017 (Epub ahead of print).

8. Kharaziha P, Chioureas D, Baltatzis G, Fonseca P, Rodriguez P, Gogvadze V, Lennartsson L, Björklund AC, Zhivotovsky B, Grandér D, et al: Sorafenib-induced defective autophagy promotes cell death by necroptosis. Oncotarget 6: 37066-37082, 2015 .

9. Bruix J, Cheng AL, Meinhardt G, Nakajima K, De Sanctis Y and Llovet J: Prognostic factors and predictors of sorafenib benefit in patients with hepatocellular carcinoma: Analysis of two phase III studies. J Hepatol 67: 999-1008, 2017.

10. Tafreshi A,Thientosapol E,Liew MS, Guo Y,QuaggiottoM,BoyerM and Davis ID: Efficacy of sorafenib in advanced renal cell carcinoma independent of prior treatment, histology or prognostic group. Asia Pac J Clin Oncol 10: 60-65, 2014.

11. Kudo M: Immune checkpoint inhibition in hepatocellular carcinoma: Basics and ongoing clinical trials. Oncology 92 (Suppl 1): S50-S62, 2017.

12. Rautenberg C, Nachtkamp K, Dienst A, Schmidt PV, Heyn C, Kondakci M, Germing U, Haas R, Kobbe G and Schroeder T: Sorafenib and azacitidine as salvage therapy for relapse of FLT3-ITD mutated AML after allo-SCT. Eur J Haematol 98: 348-354, 2017.

13. Wilhelm SM, Carter C, Tang L, Wilkie D, McNabola A, Rong H, Chen C, Zhang X, Vincent P, McHugh M, et al: BAY 43-9006 exhibits broad spectrum oral antitumor activity and targets the RAF/MEK/ERK pathway and receptor tyrosine kinases involved in tumor progression and angiogenesis. Cancer Res 64: 7099-7109, 2004.

14. Gridelli C, Maione P, Del Gaizo F, Colantuoni G, Guerriero C, Ferrara C, Nicolella D, Comunale D, De Vita A and Rossi A: Sorafenib and sunitinib in the treatment of advanced non-small cell lung cancer. Oncologist 12: 191-200, 2007.

15. Zhou Q, Guo X and Choksi R: Activation of focal adhesion kinase and Src mediates acquired sorafenib resistance in A549 human lung adenocarcinoma xenografts. J Pharmacol Exp Ther 363: 428-443, 2017.

16. Degen A, Weichenthal M, Ugurel S, Trefzer U, Kilian K, Garbe C, Egberts F, Poppe LM, Hauschild A and Gutzmer R: Cutaneous side effects of combined therapy with sorafenib and pegylated interferon alpha-2b in metastatic melanoma (phase II DeCOG trial). J Dtsch Dermatol Ges 11: 846-853, 2013.

17. Liang $\mathrm{H}$ and Wang $\mathrm{M}$ : Mechanism of c-Met in non-small cell lung cancer and its treatment and testing. Zhongguo Fei Ai Za Zhi 18: 745-751, 2015 (In Chinese). 
18. Ma PC, Jagadeeswaran R, Jagadeesh S, Tretiakova MS, Nallasura V, Fox EA, Hansen M, Schaefer E, Naoki K, Lader A, et al: Functional expression and mutations of c-Met and its therapeutic inhibition with SU11274 and small interfering RNA in non-small cell lung cancer. Cancer Res 65: 1479-1488, 2005.

19. Deying W, Feng G, Shumei L, Hui Z, Ming L and Hongqing W: CAF-derived HGF promotes cell proliferation and drug resistance by up-regulating the c-Met/PI3K/Akt and GRP78 signalling in ovarian cancer cells. Biosci Rep 37: pii: BSR20160470, 2017.

20. Gohda E, Tsubouchi H, Nakayama H, Hirono S, Sakiyama O, Takahashi K, Miyazaki H, Hashimoto S and Daikuhara Y: Purification and partial characterization of hepatocyte growth factor from plasma of a patient with fulminant hepatic failure. J Clin Invest 81: 414-419, 1988.

21. Konstorum A and Lowengrub JS: Activation of the HGF/c-Met axis in the tumor microenvironment: A multispecies model. J Theor Biol 439: 86-99, 2017.

22. Kucerova L, Demkova L, Skolekova S, Bohovic R and Matuskova M: Tyrosine kinase inhibitor SU11274 increased tumorigenicity and enriched for melanoma-initiating cells by bioenergetic modulation. BMC Cancer 16: 308, 2016.

23. Zou HY, Li Q, Lee JH, Arango ME, McDonnell SR, Yamazaki S, Koudriakova TB, Alton G, Cui JJ, Kung PP, et al: An orally available small-molecule inhibitor of c-Met, PF-2341066, exhibits cytoreductive antitumor efficacy through antiproliferative and antiangiogenic mechanisms. Cancer Res 67: 4408-4417, 2007.

24. Cascone T, Xu L, Lin HY, Liu W, Tran HT, Liu Y, Howells K, Haddad V, Hanrahan E, Nilsson MB, et al: The HGF/c-Met pathway is a driver and biomarker of VEGFR-inhibitor resistance and vascular remodeling in non-small cell lung cancer. Clin Cancer Res 23: 5489-5501, 2017.

25. Tarhini AA, Rafique I, Floros T, Tran P, Gooding WE, Villaruz LC, Burns TF, Friedland DM, Petro DP, Farooqui M, et al: PPhase 1/2 study of rilotumumab (AMG 102), a hepatocyte growth factor inhibitor, and erlotinib in patients with advanced non-small cell lung cancer. Cancer 123: 2936-2944, 2017.

26. Engelman JA, Zejnullahu K, Mitsudomi T, Song Y, Hyland C, Park JO, Lindeman N, Gale CM, Zhao X, Christensen J, et al: MET amplification leads to gefitinib resistance in lung cancer by activating ERBB3 signaling. Science 316: 1039-1043, 2007.

27. Bignold LP, Ferrante A and Haynes DR: Studies of chemotactic, chemotactic movement-inhibiting and random movement-inhibiting effects of interleukin-1 alpha and beta, tumour necrosis factor alpha and beta and interferon gamma on human neutrophils in assays using 'sparse-pore' polycarbonate (Nuclepore) membranes in the Boyden chamber. Int Arch Allergy App Immunol 91: 1-7, 1990.

28. Yamaoka T, Ohmori T, Ohba M, Arata S, Murata Y, Kusumoto S, Ando K, Ishida H, Ohnishi T and Sasaki Y: Distinct afatinib resistance mechanisms identified in lung adenocarcinoma harboring an EGFR mutation. Mol Cancer Res 15: 915-928, 2017

29. Zhao J, Fang L, Zhang X, Liang Y and Gou S: Synthesis and biological evaluation of new [1,2,4]triazolo[4,3-a]pyridine derivatives as potential c-Met inhibitors. Bioorg Med Chem 24 3483-3493, 2016.

30. Li D, Yang H, Li R, Wang Y, Wang W, Li D, Ma S and Zhang X: Antitumor activity of gambogic acid on NCI-H1993 xenografts via MET signaling pathway downregulation. Oncol Lett 10: 2802-2806, 2015.

31. Zhao L, Zhu Z, Yao C, Huang Y, Zhi E, Chen H, Tian R, Li P, Yuan Q, Xue Y, et al: VEGFC/VEGFR3 signaling regulates mouse spermatogonial cell proliferation via the activation of AKT/MAPK and cyclin D1 pathway and mediates the apoptosis by affecting caspase 3/9 and Bcl-2. Cell Cycle: 1-50, 2017.
32. Katayama R: Therapeutic strategies and mechanisms of drug resistance in anaplastic lymphoma kinase (ALK)-rearranged lung cancer. Pharmacol Ther 177: 1-8, 2017.

33. Zhu YJ, Zheng B, Wang HY and Chen L: New knowledge of the mechanisms of sorafenib resistance in liver cancer. Acta Pharmacol Sin 38: 614-622, 2017.

34. Murray M, Gillani TB, Ghassabian S, Edwards RJ and Rawling T: Differential effects of hepatic cirrhosis on the intrinsic clearances of sorafenib and imatinib by CYPs in human liver. Eur J Pharm Sci 114: 55-63, 2017.

35. Bahrami A, Hassanian SM, ShahidSales S, Farjami Z, Hasanzadeh M, Anvari K, Aledavood A, Maftouh M, Ferns GA, Khazaei M and Avan A: Targeting RAS signaling pathway as a potential therapeutic target in the treatment of colorectal cancer. J Cell Physiol 233: 2058-2066, 2018.

36. Liu H, Zhang Q, Li K, Gong Z, Liu Z, Xu Y, Swaney MH, Xiao K and Chen Y: Prognostic significance of USP33 in advanced colorectal cancer patients: New insights into $\beta$-arrestin-dependent ERK signaling. Oncotarget 7: 81223-4020, 2016

37. Li XL, Chen XQ, Zhang MN, Chen N, Nie L, Xu M, Gong J, Shen PF, Su ZZ, Weng X, et al: SOX9 was involved in TKIs resistance in renal cell carcinoma via Raf/MEK/ERK signaling pathway. Int J Clin Exp Pathol 8: 3871-3881, 2015.

38. Ranieri G, Gadaleta-Caldarola G, Goffredo V, Patruno R, Mangia A, Rizzo A, Sciorsci RL and Gadaleta CD: Sorafenib (BAY 43-9006) in hepatocellular carcinoma patients: From discovery to clinical development. Curr Med Chem 19: 938-944, 2012.

39. Sharma SV, Bell DW, Settleman J and Haber DA: Epidermal growth factor receptor mutations in lung cancer. Nat Rev Cancer 7: 169-181, 2007.

40. Bonanno L, Jirillo A and Favaretto A: Mechanisms of acquired resistance to epidermal growth factor receptor tyrosine kinase inhibitors and new therapeutic perspectives in non small cell lung cancer. Curr Drug Targets 12: 922-933, 2011.

41. Polverino A, Coxon A, Starnes C, Diaz Z, DeMelfi T, Wang L, Bready J, Estrada J, Cattley R, Kaufman S, et al: AMG 706, an oral, multikinase inhibitor that selectively targets vascular endothelial growth factor, platelet-derived growth factor, and kit receptors, potently inhibits angiogenesis and induces regression in tumor xenografts. Cancer Res 66: 8715-8721, 2006.

42. Stabile LP, Rothstein ME, Keohavong P, Lenzner D, Land SR, Gaither-Davis AL, Kim KJ, Kaminski N and Siegfried JM: Targeting of both the c-Met and EGFR pathways results in additive inhibition of lung tumorigenesis in transgenic mice. Cancers (Basel) 2: 2153-2170, 2010

43. Wu YL, Soo RA, Locatelli G, Stammberger U, Scagliotti G and Park K: Does c-Met remain a rational target for therapy in patients with EGFR TKI-resistant non-small cell lung cancer? Cancer Treat Rev 61: 70-81, 2017.

44. Martinez-Marti A,FelipE,Matito J,Mereu E,Navarro A,Cedrés S, Pardo N, Martinez de Castro A, Remon J, Miquel JM, et al: Dual MET and ERBB inhibition overcomes intratumor plasticity in osimertinib-resistant-advanced non-small-cell lung cancer (NSCLC). Ann Oncol 28: 2451-2457, 2017.

45. Chen JC, Chuang HY, Hsu FT, Chen YC, Chien YC and Hwang JJ: SSorafenib pretreatment enhances radiotherapy through targeting MEK/ERK/NF- $\mathrm{B}$ pathway in human hepatocellular carcinoma-bearing mouse model. Oncotarget 7: 85450-85463, 2016.

46. Pisanu ME, Noto A, De Vitis C, Morrone S, Scognamiglio G, Botti G, Venuta F, Diso D, Jakopin Z, Padula F, et al: Blockade of Stearoyl-CoA-desaturase 1 activity reverts resistance to cisplatin in lung cancer stem cells. Cancer Lett 406: 93-104, 2017. 